\title{
PENINGKATAN KOMITMEN PROFESIONAL GURU SMP MELALUI PENGUATAN EFIKASI DIRI DAN BUDAYA ORGANISASI
}

\author{
Ida Zuraida $^{\left.q^{*}\right)}$, Rita Retnowati ${ }^{\left.b^{*}\right)}$, Rais Hidayat ${ }^{\left.b^{*}\right)}$ \\ a) Sekolah SMN 3 Leuwiliang, Bogor, Indonesia \\ ${ }^{b)}$ Universitas Pakuan, Bogor, Indonesia \\ *)e-mail korespondensi: rais.hidayat@unpak.ac.id
}

riwayat artikel : diterima: 18 Juni 2020; direvisi: 22 Juni 2020; disetujui: 06 Juli 2020

\begin{abstract}
Abstrak. Penelitian ini bertujuan untuk menemukan upaya-upaya yang dapat dilakukan dalam rangka meningkatkan Kompetensi Profesional Guru SMP melalui kajian terhadap hubungan Efikasi Diri Dan Budaya Organisasi se Komisariat Leuwiliang Dan Cibungbulang. Penelitian ini dilakukan dengan metode surve dengan pendekatan korelasional. Kesimpulan yang diperoleh adalah : 1). Terdapat hubungan positif yang signifikan antara efikasi diri dengan komitmen profesional dengan koefesien korelasi $\left(\mathrm{r}_{\mathrm{y} 1}\right)$ sebesar 0,853 dengan persamaan regresi $\hat{Y}=19,787+0,878 X$. dengan koefesian detreminasi 0,783 . 2). Terdapat hubungan positif yang signifikan antara budaya organisasi dengan komitmen profesional dengan koefesien korelasi $\left(\mathrm{r}_{\mathrm{y} 2}\right)$ sebesar 0,227 dengan persamaan regresi $\hat{Y}=119,436+0.266 \mathrm{X}_{2}$ dengan koefesian detreminasi 0,051. 3). Terdapat hubungan positif dengan yang signifikan antara efikasi diri dan budaya organisasi dengan komitmen profesional dengan koefesien korelasi $\left(\mathrm{r}_{\mathrm{y} 12}\right)$ sebesar 0,853 dengan persamaan regresi $\hat{Y}=17,128+0,827 x_{1}+0.029 x_{2}$. Koefesian detreminasi 0,7284$)$. Terdapat hubungan yang dominan pada efikasi diri $\left(\mathrm{X}_{1}\right)$ dari budaya organisasi $\left(\mathrm{X}_{2}\right)$ pada komitmen profesional guru $(\mathrm{Y})$. dengan koefesien korelasi efikasi diri dengan komitmen profesional $\left(\mathrm{r}_{\mathrm{y} 1}\right)$ sebesar 0,853. Dan koefesien korelasi budaya organisasi dengan komitmen profesional $\left(\mathrm{r}_{\mathrm{y} 2}\right)$ sebesar 0,227. 5). Terdapat faktor-faktor lain yang turut berpengaruh atau berhubungan terhadap peningkatan komitmen profesional selain efikasi diri dan komitmen profesional diantaranya : a). kepemimpinan transformasional, b). (OCB) Organizational Citizenship Behavior, c). iklim organisasi, d). motivasi guru.
\end{abstract}

Kata Kunci: efikasi diri, budaya organisasi, komitmen profesional

\section{IMPROVING THE PROFESSIONAL COMMITMENT OF SMP TEACHERS THROUGH STRENGTHENING SELF- EFFICATION AND ORGANIZATIONAL CULTURE}

\begin{abstract}
This study is intended to determine the efforts needed that can be implemented in order to improve the Professional Competence of Junior High School Teachers through a study of relationship of Self-Efficacy and Organizational Culture in the Commissariat of Leuwiliang and Cibungbulang This research was conducted by using a survey method of a correlational approach. The conclusions obtained were: 1). There was a significant positive relationship between self-efficacy and professional commitment where the correlation coefficient (ry1)was 0.853 , the regression equation $\hat{Y}=19.778+0.878 \mathrm{X}$ and coefficient of determination 0.783. 2). There was a significant positive relationship between organizational culture and professional commitment where the correlation coefficient (ry2) was 0.227 and a regression equation $\hat{Y}=119.436+0.266 \mathrm{X} 2$ and determination coefficient was 0.051 .3 ). There was a positive and significant relationship between self-efficacy and organizational culture and professional commitment where the correlation coefficient (ry12) was 0.853 and a regression equation $\hat{Y}=17.128+0.827 \times 1+0.029 \times 2$. Determination coefficient was 0.7284 ). There was a dominant relationship in self-efficacy (X1) of organizational culture (X2) on teacher professional commitment (Y), where the correlation coefficient of self-efficacy with professional commitment (ry1) was .0853. The correlation coefficient between organizational culture and professional commitment (ry2) was 0.227. 5). There were other factors that influencing or relating to increasing professional commitment, they were: a). transformational leadership, b). Organizational Citizenship Behavior (OCB), c). organizational climate, d). teacher motivation.
\end{abstract}

Keywords: self-efficacy, organizational culture, professional commitment.

\section{PENDAHULUAN}

Sumber daya manusia merupakan salah satu faktor untuk meningkatkan mutu pendidikan adalah melalui pendidikan. Dengan ilmu pengetahuan, pendidikan akan terlihat perkembangannya, hal ini dapat ditunjukan makin majunya peradaban manusia terhadap perkembangan teknologi disetiap bidang. Sejalan dengan perkembangan zaman tersebut, guru adalah satu yang memegang kunci keberhasilan didunia pendidikan. Guru ialah individu yang sangat berpengaruh dalam kegiatan belajar mengajar, tanpa guru maka kegiatan pembelajaran tidak akan terlaksana. Oleh sebab itu seorang guru diharapkan dapat mengubah cara pandang siswanya, agar siswa berwawasan luas dan bagi seorang guru harus memiliki berbagai kriteria sebagai seorang guru yang professional. Komitmen profesional guru adalah suatu keterikatan diri terhadap tugas dan kewajiban sebagai guru yang dapat melahirkan tanggung jawab, sikap responsif dan inovatif terhadap perkembangan ilmu pengetahuan dan teknologi. Dari itu tidak mengherankan, jika seorang guru yang profesional akan nampak lebih giat dan semangat untuk 
melakukan pekerjaannya

Oleh karena itu guru diharapkan memiliki standar kualitas pribadi yang telah ditentukan, berwibawa, efikasi diri, budaya organisasi, komitmen kerja dan keyakinan akan kemampuan diri sendiri serta kemampuan mengolah sumber-sumber tindakan untuk mengelola situasi yang akan diahadapi. Pada saat sekarang ini perubahan-perubahan di dalam dunia pendidikan sangatlah pesat yang dikarenakan globalisasi tingkat dunia, oleh karena itu diharapkan seorang guru untuk memiliki kemampuan yang memadai dengan keyakinan diri yang tinggi.Guru juga harus memiliki dorongan dari dalam diri guru sendiri, dengan ketekunan serta keuletannya dalam menekuni semua tujuan yang tersirat dalam dunia keguruan yaitu mencerdaskan anak bangsa. Seorang guru hendaknya juga memiliki komitmen didalam dirinya akan tugas dan kewajibannya. Untuk menunjang semua itu seorang guru harus menguasai ilmu pengetahuannya, oleh karena itu dibutuhkan pelatihan-pelatihan yang sesuai dengan bidangnya. Diera globalisasi sekarang ini, masih banyak guru yang kurang maksimal dalam menjaga komitmen sebagai guru. Hal ini terlihat masih banyaknya guru yang masih mengabaikan akan tugas pokoknya yanitu mengajar. Pada jam-jam tertentu masih banyak terlihat guru tingkat SMP komisariat Leuwiliang dan Cibungbulang yang mengulu-ulur waktu dalam mengajar, hal ini menunjukan guru kurang semangat, tidak sepenuh hati, loyalitas terhadap komitmen profesional guru masih kurang, kurang tekun, kurang memfokuskan pelayanan kepada peserta didik.untuk tercapainya tujuan pendidikan foktor utama adalah terletak pada tingginya komitmen profesional pada guru.

Menurut Arranya dan Ferris, (2008:67) menyatakan bahwa komitmen profesional adalah suatu kepercayaan dan kemauan usaha ysng sungguh-sungguh serta memelihara keanggotaan terhadap tujuan tujuan dan nilai- nilai profesi. Menurut Larkin (dalam Trisnaningsih, 2003:65) menyatakan bahwa komitmen profesional dapat dikatakan sebagai tingkat loyalitas individu pada profesinya seperti seperti apa yang dipersepsikan oleh individu tersebut. Masih dari kutipan yang sama, suatu komitmen profesional pada dasarnya merupakan suatu persepsi yang berintikan loyalitas, tekad, dan harapan seseorang dengan disusun oleh system nilai atau norma yang akan mengarahkan orang tersebut untuk bertindak atau bekerja sesuai dengan prosedur-prosedur tertentu dalam upaya menjalankan tugasnya dengan tingkat keberhasilan yang tinggi. Menurut Tranggono dan Andi, (2008:77) menyatakan bahwa Komitmen profesional dapat diartikan sebagai tingkat kesetiaan seseorang terhadap pekerjaanya sesuai dengan apa yang menjadi persepsi dari orang tersebut. Berdasarkan teori komitmen profesional di atas, maka dapat disintesiskan bahwa komitmen profesional adalah suatu persepsi yang berintikan loyalitas, tekad, dan harapan seseorang terhadap profesinya yang disusun oleh system nilai atau norma agar bekerja sesuai dengan prosedur untuk keberhasilan yang tinggi, dengan indikator sebagai berikut : 1) Keteguhan mengerjakan sesuatu dengan penuh semangat 2) Berusaha secara maksimal untuk kepentingan profesi, 3) Mempunyai loyalitas, tekad dan harapan yang sesuai dengan prosedur untuk mencapai keberhasilan, 4) memiliki tujuan dan nilai-nilai profesi, 5) Memelihara keanggotaan dalam profesi.

Menurut. Bandura (2008:122) menyatakan bahwa efikasi diri merupakan penilaian seseorang terhadap kemampuannya dalam bertindak untuk meningkatkan kinerja. Luthans (2011:98) menyatakan bahwa efikasi diri merupakan keyakinan individu terhadap kemampuannya dalam menggerahkan motivasinya, sumber pengetahuannya dan caranya bertindak sehingga berhasil dalam melakukan tugas-tugas khusus sesuai dengan konteks yang telah ditentukan. Menurut Steven (2008:56), menyatakan bahwa efikasi diri merujuk pada keyakinan individu bahwa dirinya mampu menjalankan suatu tugas. Menurut Luthans (2011:76), sumber utama efikasi adalah (1) penguasaan pengalaman atau prestasi kerja; (2) Pengalaman sendiri aau peniruan; (3) bujukan sosial. Keyakinan orang pada kemampuannya bisa diperkuat diperkuat oleh orang lain yang cakap dalam membujuknya bahwa dirinya bisa melakukan apa yang diperlukan dan memberikan hasil positif pada kemajuan yang dibuat dibidang Khusus ini; (4) kebangkitan fisiologi dan fsikologi. Jika individu berada dalam kondisi fisik dan mental sangat baik, ini bisa berfungsi sebagai titik tolak untuk membangun kemampuan dengan cara lain dan bisa membangkit kemampuan seseorang pada tugas yang menuntut secara fisik dan atau fsikologi. Berdasarkan teori di atas dapat disintesiskan bahwa efikasi diri adalah keyakinan pada diri seseorang akan kesanggupan dirinya dalam melaksanakan suatu tugas dengan baik. Adapun indikatornya adalah : 1) Kesanggupannya menyelesaikan tugas 2) kebangkitan fisiologi dan Psikologi 3) Bekerja secara maksimal dalam setiap tugas 4) Mampu menyelesaikan kesulitan yang dihadapi. 5) penguasaan pengalaman dan prestasi kerja.

Menurut Kreitner dan Kinicki, (2005:85) menyatakan bahwa budaya organisasi seringkali digambarkan dalam arti nyang dimiliki bersama. Pola-pola dari kepercayaan, simbol-simbol, ritual-ritual dan mitos-mitos yang berkembang dari waktu ke waktu dan berfungsi sebagai perekat yang menyatukan organisasi. Budaya organisasi dapat diartikan pula sebagai nilai-nilai yang dalam pelaksanaan oleh anggotanya dapat diterima atau tidak, suatu pendapat serta keyakinan, rambu-rambu yang harus diperhatikan bilamana seseorang akan bergabung ke dalam organisasi tersebut.. Menurut Nawawi (2003:87) Yang dikutip dari Cushway B dan Lodge D, hubungan budaya dengan budaya organisasi, bahwa " budaya organisasi adalah suatu kepercayaan dan nilai-nilai yang menjadi falsafah utama yang dipegang teguh oleh anggota organisasi dalam menjalankan atau mengoperasionalkan kegiatan organisasi”. Menurut Nawawi (2003:65) yang dikutip dari Schemerhom, Hurn dan Obson, nenyaatakan "budaya organisasi adaalah suatu system penyebaran keyakinan dan nilai-nilai yang dikembangkan didalam suatuorganisasi sebagai perilaku anggotanya". Menuerut Tunstal dalam Wirawan (2007:89) mendefinisikan, budaya organsasi adalah suatu kebiasaan, nilai, norma dan perilaku serta cara melakukan bisnis yang unik bagi setiap organisasi yang mengatur pola aktivitas dan tindakan organisasi, serta melukiskan pola implisit, perilaku, dan emosi yang muncul yang menjadi karakteristik dalam organisasi. Berdasarkan teori di atas dapat disintesiskan bahwa budaya organisasi adalah suatu pedoman, nilai, dan norma perilaku yang diakui dan disosialisasikan secara terus menurus sebagai pembentuk karakteristik suatu organisasi dan cara indifidu atau kelompok bekerja sama untuk menyelesaikan tugas. dengan indikator adalah sebagai berikut: 
(1) Sensitivitas pada kebutuhan pelanggan (siswa) dan pekerja (guru), (2) Nilai-nilai yang diyakini anggota organisasi, (3) Nilainilai yang dikembangkan dalam suatu organisasi, (4) cara-cara bekerja yang dianut bersama oleh anggota organisasi (5) Kebiasaan, nilai, norma dan perilaku

\section{METODE PENELITIAN}

Metode penelitian yang digunakan dalam penelitian ini adalah metode suvei dengan pendekatan kolerasional, yaitu pendekatan yang berupaya untuk mengemukakan ada tidaknya huibungan variabel bebas dengan variabel terikat". Variabel penelitian ini terdiri dari dua variabel bebas dan satu variabel terikat, variabel bebas adalah efikasi diri $\left(\mathrm{X}_{1}\right)$ dan budaya organisasi $\left(\mathrm{X}_{2}\right)$, sedangkan variabel terikatnya adalah komitmen profesional $(\mathrm{Y})$. Metode pengumpulan datanya menggunakan angket atau kuisioner. Bentuk lebaran angket dapat berupa sejumlah pertanyaan tertulis, dengan tujuan agar mendapat informasi dari responden tentang apa yang mereka dapatkan mengenai beberapa variabel untuk dijadikan sumber data dalam penelitian ini. Instrumen yang digunakan untuk mengukur variabel terkait $(\mathrm{Y})$, yaitu Komitmen profesional,dan Variabel bebas yaitu efikasi diri $\left(\mathrm{X}_{1}\right)$, budaya Organisasi $\left(\mathrm{X}_{2}\right)$.

\section{HASIL DAN PEMBAHASAN}

\section{Hubungan Antara Efikasi Diri $\left(\mathbf{X}_{1}\right)$ dengan Komitmen Profesional (Y)}

Hasil penelitian menunjukkan bahwa terdapat hubungan positif antara efikasi diri dengan komitmen profesional . Hal ini ditunjukkan oleh koefisien korelasi (ry.1) sebesar 0,853 yang dinyatakan sangat signifikan. Keragaman pada komitmen profesional yang terkait erat dengan efikasi diri tercermin dari nilai koefesien determinasi (r2y.1) sebesar 0,728 yang dimaknai $72,8 \%$ keragaman pada komitmen profesional dapat dijelaskan oleh efikasi diri, sedangkan $27,2 \%$ sisanya di pengaruhi oleh faktor lain. Konstanta kemiringan (a) 19.787 dengan konstanta b sebesar 0.878 sehingga persamaan regresi yang terbentuk antara variabel efikasi diri dengan komitmen profesional yaitu $\hat{Y}=19.787+0.878$ X1. Hasil penelitian ini menyimpulkan bahwa Efikasi Diri yang dimiliki memberikan kontribusi positif yang berpengaruh nyata terhadap komitmen profesional. Pada hakikatnya efikasi diri adalah keyakinan pada diri seseorang akan kesanggupan dirinya dalam melaksanakan suatu tugas dengan baik. Adapun indikatornya adalah : 1) Kesanggupannya menyelesaikan tugas 2) kebangkitan fisiologi dan Psikologi 3) Bekerja secara maksimal dalam setiap tugas 4) Mampu menyelesaikan kesulitan yang dihadapi. 5) penguasaan pengalaman dan prestasi kerja Guru sebagai peran utama dalam proses pembelajaran tentu dihadapkan dengan situasi pribadinya sendiri. Guru yang cerdas dan cermat akan mengungkapkan kreativitas yang ada dalam dirinya. Salah satunya dengan efikasi diri seorang guru. Salah satu indikator dari efikasi diri adalah kepercayaan akan kemampuan untuk mengungkapkan potensi diri. Kepercayaan akan kemampuan diri dalam diri seorang guru akan menumbuhkan sikap kreativitas, karena tidak semua guru mampu mengungkapkan apa potensi yang ada dalam dirinya. Kreativitas tidak akan muncul jika efikasi diri dalam seorang guru tidak dimaksimalkan. Hal ini sesuai dengan hasil penelitian sebelumnya yaitu Greety dan Samual yang berjudul "Effect Of Enpowerment, Self Eficacy, and Lecturer To Proffession's Commitment Of The Manado State Univercity" (Internasional Journal of Business management Invention, 2014: 115) menyimpulkan bahwa terdapat pengaruh positif yang signifikan antara evikasi diri (X1) dengan Komitmen Profesional $(\mathrm{Y})$ koefisien jalur $=0.736,8(\mathrm{t}$-count $=14.680>\mathrm{t}$-tabel $=1.98$ dengan $\alpha=0,05)$. Semakin tinggi efikasi diri semakin tinggi pula komitmen profesional guru. Dengan demikian temuan fakta dan data dalam analisis penelitian ini semakin mendukung temuan-temuan terdahulu mengenai adanya hubungan yang kuat antara efikasi diri terhadap komitmen professional baik secara langsung ataupun tidak langsung. Berdasarkan hasil penelitian dan pembahasan di atas, maka dapat diindikasikan bahwa komitmen profesional dapat ditingkatkan melalui penguatan Efikasi Diri

\section{Hubungan Antara Budaya Organisasi $\left(\mathrm{X}_{2}\right)$ dengan Komitmen Profesional Guru $(\mathrm{Y})$}

Hasil penelitian menunjukkan bahwa terdapat hubungan positif antara budaya organisasi dengan komitmen profesional . Hal ini ditunjukkan oleh koefisien korelasi (ry.2) sebesar 0,227 yang dinyatakan signifikan. Keragaman pada komitmen profesional yang terkait erat dengan budaya organisasi tercermin dari nilai koefesien determinasi (r2y.2) sebesar 0,051 yang dimaknai 5,1\% keragaman pada komitmen profesional dapat dijelaskan oleh budaya organisasi, sedangkan 94,4\% sisanya di pengaruhi oleh faktor lain. Konstanta kemiringan (a) 110.436 dengan konstanta b sebesar 0.266 sehingga persamaan regresi yang terbentuk antara variabel budaya organisasi dengan komitmen profesional guru yaitu $\hat{Y}=110.436+0.266$ X2. Hasil penelitian ini menyimpulkan bahwa budaya organisasi yang dimiliki memberikan kontribusi positif yang berpengaruh nyata terhadap komitmen profesional. Pada hakikatnya budaya organisasi adalah suatu kepercayaan, pedoman, nilai, dan norma perilaku yang diakui dan disosialisasikan secara terus menurus sebagai pembentuk karakteristik suatu orgamisasi dan cara indifidu atau kelompok bekerja sama untuk menyelesaikan tugas. dengan indikator adalah sebagai berikut: (1) Sensitivitas pada kebutuhan pelanggan (siswa) dan pekerja (guru), (2) Nilai-nilai yang diyakini anggota organisasi, (3) Nilai-nilai yang dikembangkan dalam suatu organisasi, (4) cara-cara bekerja yang dianut bersama oleh anggota organisasi (5) Kebiasaan, nilai, norma dan perilaku. Hal ini juga sesuai dengan hasil penelitian Wahyuning (2016: 115) dengan judul" Pengaruh Budaya Organisisasi, Komitmen, Motivasi berprestasi, Terhadaf Profesionalisme Guru SDN Kecamatan Abang Tinggi Kabupaten 
Lampung Utara".Tesis. Universitas Lampung: Bandar Lampung. Hasil penelitian menunjukan bahwa t-hitung untuk fareabek budaya organisasi sebesar 16,343 dan tingkat signifikan (sig) 0,00. Sedangkan t-tabel dengan $\mathrm{dk}=101-3=98$ dan alpa $=$ 0,05diperoleh 1,984, denan demikian t-hitung $>$ t-tabel atau 16,34>1,984dan sig 0,018<0. Semakin tinggi budaya organisasi semakin tinggi pula komitmen profesional guru. Sekolah merupakan salah satu wadah organisasi yang didalamnya ada beberapa unsur, antara lain kepala sekolah, guru, tenaga administrasi, dan siswa. Setiap individu memiliki nilai, asumsi, sikap, keyakinan diri dan perasaan yang berbeda-beda. Dari semua unsur di atas saling berhubungan antara satu dengan yang lainnya terbentuklah suatu budaya organisasi yang baru, sehingga sesama anggota akan bahu membahu untuk memajukan budaya organisasi di sekolah tersebut dan menciptakan nilai yang baru. budaya organisasi adalah sebuah persepsi dimana anggota organisasi menerima dan memahaminya melalui apa yang dialaminya dalam organisasi. Budaya organisasi bersifat deskriptif, yaitu berkenaan dengan bagai mana anggota organisasi menerima dan mengartikan budaya tersebut. Anggota organisasi mengartikan dan mengutarakan budaya organisasi dengan cara yang sama (Shared - penerimaan atau pengamatan bersama) walaupun latar belakang yang berbeda. Budaya yang menanamkan nilai-nilai utama secara kokoh dan diterima secara luas dikalangan anggota orgnisasi dan memiliki pengaruh yang besar terhadap perilaku anggota organisasi, itulah yang disebut dengan budaya yang kuat. Dengan demikian temuan fakta dan data dalam analisis penelitian ini adalah komitmen profesional guru dapat ditingkatkan melalui penguatan budaya organisasi.

\section{Hubungan Efikasi Diri $\left(X_{1}\right)$ dan Budaya Organisasi $\left(X_{2}\right)$ Secara Bersama-sama dengan Komitmen Profesional $(\mathbf{Y})$.}

Hasil penelitian menunjukkan bahwa terdapat hubungan positif antara efikasi diri dan budaya organisasi secara bersama-sama dengan komitmen profesional guru. Hal ini ditunjukkan oleh koefisien korelasi (ry.12) sebesar 0,853 yang dinyatakan sangat signifikan setelah diuji dengan uji F. Keragaman pada komitmen profesional yang terkait erat dengan efikasi diri dan budaya organisasi tercermin dari nilai koefesien determinasi (r2y.12) sebesar 0,728 yang dimaknai 72,8\% keragaman pada komitmen profesional dapat dijelaskan oleh budaya organisasi, sedangkan $27,2 \%$ sisanya di pengaruhi oleh faktor lain. Pola hubungan antara variabel efikasi diri dan budaya organisasi secara bersama-sama terhadap variabel komitmen profesional guru ditunjukkan dengan persamaan regresi linier ganda $\hat{Y}=17,128+0,827 \mathrm{X} 1+0.029 \mathrm{X} 2$ dengan koefisien regresi yang dinyatakan sangat signifikan. Guru harus memiliki komitmen terhadap pekerjaanya sebagai pengajar, sehingga dengan demikian pendidikan akan tercapai tujuannya dengan baik. Seorang guru dapat melaksanakan tugasnya dengan baik harus dibekali kepercayaan dan kenyakinan diri untuk dapat menyelesaikan tugasnya dengan baik. Dimana kepercayaan menyelesaikan tugas dengan baik harus dibarengin dengan komitmen professional guru yang tinggi. Dengan adanya budaya organisasi dapat diketahui nilai nilai luhur yang dijunjung kepercayaan, pedoman, dan norma perilaku yang diakui dan disosialisasikan secara terus menerus sebagai pembentuk karakteristik organisasi dalam menghadapi perubahan jaman atau adaptasi dari luar dan dari dalam organisasi sehingga dapat memotivasi untuk meningkatkan komitmen professional guru. Hal ini juga sesuai dengan hasil penelitian Rahayuono (2018:100) "Analisis Komitmen Profesional Guru melalui Efikasi Diri dan Budaya Organisasi Pada Guru PNS SMPN se sub rayon Kecamatan Ciawi Kabupaten Bogor". Hasil penelitian menunjukan terdapat hubungan yang positip antara efikasi diri [X1] Dengan komitmen professional guru[Y] dengan nilai signifikan uji $\mathrm{T}<$ $0,05[0,045<0,05]$, terdapat hubungan positip antara budaya organisasi [X2] dengan komitmen profesionakgru [Y] dengan nilai signifikan uji $\mathrm{t}<0,05[0,006<0,05]$. Persamaan regresi vareabel tersebut yaitu $85,251+0,272 \mathrm{X} 2$. Terdapat hubungan positif antara fareabel efikasi diri dengan budaya organisasi Bersama sama dengan komitment professional guru dengan nilai signifikan uji $\mathrm{F}<0,05[0,02<0,05]$. Berdasarkan hasil penelitian yang dikemukakan di atas, dapat disimpulkan bahwa komitmen profesional dapat ditingkatkan melalalui penguatan efikasi diri dan budaya organisasi

\section{SIMPULAN}

Berdasarkan analisis terhadap data hasil penelitian dapat disimpulkan terdapat hubungan positif sangat signifikan antara Efikasi Diri dengan Komitmen Profesional, Budaya Organisasi dengan Komitmen Profesional dan Efikasi Diri dan Budaya Organisasi bersama-sama dengan Komitmen Profesional. Berdasarkan hasil penelitian ini maka untuk meningkatkan Komitmen Profesional dapat dilakukan dengan penguatan efikasi diri dan Budaya Organisasi

\section{REFERENSI}

Arranya, N. \& K. Ferris, (1984). 'A Reexamnination of accountants ' Organizational-Professional Conflict. The Accounting Review, vol. 59, 1-15.

Bandura. Albert. (2004). Self-Efficacy Biliefs of adolescent, Volume in adolescence and Education, Chap,5: Teacher Self-Efficacy. Emory University: Urdan and Pajares Editor.

Kreitner dan Kinicki. (2005). Perilaku Organisasi. Jakarta : Salemba Empat

Luthan Fred. (2011) Organizational Behavior, United State of Amerika: McGraw-Hill.

Nawawi Hadari. (2003). Managemen Sumber Daya Manusia Yang Kompetitif. Yogyakarta: Gajah Mada Press.

Soewarto Hardhienata. (2017). IOP Publication Series, Sitorem, Vol.166. 
Steven Robins P., Judge A Timothy, Alih Bahasa Diana Angelica, $\{2008\}$ Perilaku Organisasi Edisi 12,Jakarta, Salemba 4. Trangono, Rahardian P. , Andi Lartika. (2008). Pengaruh Komitmen Organisasi dan Profesional Terhadap Kepuasan Kerja Auditor Dengan Motivasi Sebagai Vareabel Intervening. Jurnal Bisnis dan Ekonomi (JBE)15(1), pp. 80-90

Trisnaningsih, Sri, (2007). Indepedensi Auditorium dan Komitmen Organisasi Sebagai Mediasi Pengaruh Pemahaman Good Gavermance, Gaya Kepemimpinan dan Budaya Organisasi Terhadap Kinerja Auditor. Jurnal Simposium Nasional Akutansi X. Unhas Makasar.

Wirawan. (2007). Budaya dan Iklim Organisasi. Jakarta: Salemba empat. 